\title{
Objective and subjective quality of life in adults with autism spectrum disorders in southern Spain
}

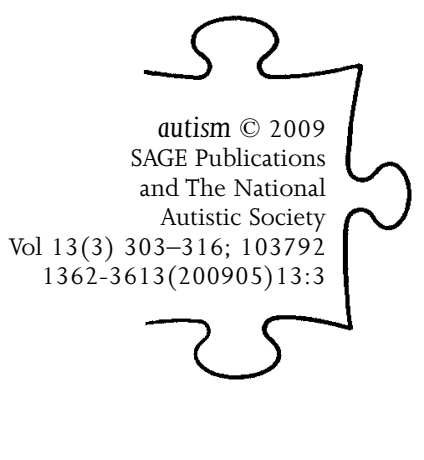

DAVID SALDAÑ

ROSA M. ÁLVAREZ

SILVIA LOBATÓN
University of Seville, Spain

Autismo Andalucía and University of Seville, Spain

A N A M. L O P E Z University of Seville, Spain

M A C A R E A MOR E N O Autismo Andalucía, Spain

M I G U E L R O J A N O Autismo Andalucía, Spain

A B S T R A C T Subjective and objective measures of quality of life (QoL) were obtained for adults with autism spectrum disorders (ASDs) living in Andalusia (Spain). Seventy-four families responded to questionnaires about objective QoL indicators such as employment, health, adaptive behaviour and social network, and were asked to act as proxies for subjective QoL measures. Outcome on objective QoL was extremely poor. Social networks were most frequently composed of family members. Community-oriented resources were absent in most cases. For two-thirds of the families, the ability to act as proxies for subjective QoL was seriously limited by the participants' poor social and communicative abilities. The results are indicative of the need for additional support to families of adults with ASD and increased community-based resources. Further conceptualization of indicators and measurement of subjective QoL in individuals with severe disabilities and ASD is also needed in order to include their own perspective in the evaluation of service provision.

ADDRESS Correspondence should be addressed to: DAVID SALDAÑ A, Departamento de Psicología Evolutiva y de la Educación, Universidad de Sevilla, Avda. Camilo José Cela s/n, 41018 Sevilla, España. e-mail: dsaldana@us.es

Improved quality of life (QoL) is increasingly seen as the main objective of service providers for persons with disability worldwide. As such, the concept itself has received a great deal of attention and has been the centre of much debate (Schalock and Verdugo, 2002). Although there are many

Y W O R D S

adults; ASD; quality of life; Spain 
definitions of QoL, there is also a general consensus that it is a multidimensional construct. In a recent review, Schalock (2004) indicated the main domains that appear in most research in the field and that are thus considered core aspects of QoL. They include emotional wellbeing, interpersonal relations, material wellbeing (such as financial status, employment and housing), personal development (i.e. education, personal competence and performance), physical wellbeing (health, activities of daily living and leisure), self-determination, social inclusion and human and legal rights. Multidimensionality refers not only to the aspects that are measured, but also to the indicators that should be taken into account to reflect adequate QoL. This has led to the inclusion of subjective indicators based on the perceptions of users of social, health and educational services, together with traditional objective measures of outcome and service provision.

There are a certain number of studies that have analysed QoL in adults with autism spectrum disorders (ASDs). In most cases, objective indicators in different domains have pointed to very poor outcome. One of the first studies in the field followed up on persons diagnosed in the 1950s and 1960s (Rutter, 1970). It found, for example, that only three of 38 adults over the age of 16 were employed. Lotter (1974a; 1974b) and Howlin et al. (2000; Mawhood et al., 2000) found similar results in other studies in the United Kingdom. Only one out of 23 participants in Gillberg and Steffenburg's (1987) Swedish study was self-sufficient and, more recently, Billstedt et al. (2005) found that just three of their 120 participants lived independently.

Many of the participants of these studies had severe disabilities. However, other research, looking at higher-functioning individuals, has found results only marginally better. Tantam (1991) followed up on the outcome of 46 young adults, of which only five had an IQ score below average. He found that only four were employed, and most lived in an institution or with their parents. In Japan, a study showed a 20 percent employment rate, with all participants living with parents (Kobayashi et al., 1992). Other studies have found employment and independent living rates that are below 40 to 50 percent in all cases (Ballaban-Gil et al., 1996; Howlin et al., 2004; Renty and Roeyers, 2006; Rumsey et al., 1985).

Related to these results are the findings of low scores in adaptive behaviour and social relationships in adults with ASD. Only three of 22 participants in a study in Canada and North Carolina had reached normal scores in adaptive behaviour (Venter et al., 1992). Scores for everyday living skills were also very low in many of the other outcome studies, and disruptive and atypical behaviours were apparent in a great number of the participants (Billstedt et al., 2007; Eaves and Ho, in press; Howlin et al., 2000; Mawhood et al., 2000). 
Subjective measures are less frequently used in adult studies with ASD. A notable recent exception is a study by Renty and Roeyers (2006). Using a QoL questionnaire, they found that perceived informal social support was a major predictor of subjective QoL in this population, whereas individual characteristics, such as IQ score or autistic symptoms, were not. Their participants, however, were all high-functioning individuals. Subjective measures are harder to use with individuals with ASD that have greater communicative or cognitive difficulties. Traditionally, when individuals with disabilities have severe communication problems, proxy informants have been used to establish their perception of general wellbeing (Verdugo et al., 2005). Although the use of proxy measures presents certain validity problems, to date there are very few alternatives. In some cases, simplifications and adaptations of questionnaires used with the general population have been developed (Cummins, 1997). In this study, we shall be using proxy measures in order to reflect the participants' perception of their own QoL, due to their communicative and cognitive limitations.

Our study looks at objective and subjective indicators of wellbeing in adults with ASD in Andalusia. Andalusia is the largest region in Spain, occupying the southern part of the country. Although ASDs have been acknowledged in the health and educational systems over the past years, services are growing slowly. Rates of detection are increasing, but are still below prevalence expected figures (Aguilera et al., 2007), especially in the case of adults (Saldaña et al., 2006). Most research, however, is aimed at the child population with ASD. The only study reported in the past that included QoL in adults with ASD was carried out in the Madrid region (Belinchón, 2001), showing poor and inadequate provision for adolescents and adults with respect to housing, leisure and employment.

The specific aims of the study are therefore:

1 to determine the outcome in terms of adaptive behaviour, social development, independent living and employment status of adults with ASD

2 to assess the degree of support being provided to these individuals

3 to assess their quality of life in terms of objective and subjective measures, as well as testing proxy-based questionnaire procedures.

\section{Method}

\section{Participants}

Seventy-four adults with ASD and a mean age of 24.6 years $(\mathrm{SD}=5.8$, range 18.4-40.1) from the eight provinces of Andalusia took part in the study. Eighty-five percent of them were males. Most had received diagnoses of autism (65\%) or Asperger syndrome (10\%), with the remainder labelled 
generically as persons with pervasive developmental disorders (PDDs) or ASDs. Eighty-three percent of the families of these adults were members of ASD support groups. There were no significant differences between the participants in this study and those of a broader prevalence study in terms of province of residence or gender (Saldaña et al., 2006). They were, however, slightly younger (mean $=27.4$, $\mathrm{SD}=7.9$ for the prevalence study participants).

\section{Instruments and procedure}

The families of the participating adults were contacted as part of a major study reviewing the prevalence of ASD in adulthood in Andalusia. The nine existing support groups, all individuals diagnosed with ASD registered with the Regional Social Services Department, and the Andalusian Division of the Federation of Support Groups for Persons with Intellectual Disabilities (FEAPS) were contacted, together with specific well-known private clinicians. Each of these sources contacted the participants on their databases and forwarded a consent form prepared by the research team. Families and individuals wishing to participate in the study were reached by telephone in order to ensure they met the criterion of having received a diagnosis of ASD by an experienced clinician. Generic diagnoses of ASD and PDD were accepted in view of common practice among Spanish clinical psychologists and psychiatrists at the time of diagnosis of this population.

Families and persons with ASD were interviewed in their homes or in the offices of support groups. Parents responded to the Inventory for Client and Agency Planning (ICAP: Bruininks et al., 1993) for adaptive behaviour measures and a modified version of the Childhood Autism Rating Scales (CARS: Schopler et al., 1980) that included all items except one, for autistic symptom scores. Items from the Disability Assessment Schedule (DAS: Holmes et al., 1982) were used for additional measures of social interaction and language. Quality of life was assessed using items from the Comprehensive Quality of Life Questionnaire (ComQol: Cummins, 1997), as well as a questionnaire about the personal circumstances of the adult with ASD, and his/her social network and supports and services. The subjective items of the ComQol require proxies to rate the importance and satisfaction on a five-point Likert-type scale of seven domains in the life of the person with disability. The domains included in the questionnaire are material wellbeing, health, productivity, intimacy, safety, place in community and emotional wellbeing. Subjective quality of life is obtained as a result of the product of importance and satisfaction scores for each individual in each domain.

The intimacy scale, which measures importance and satisfaction of relationships with family and friends, was divided into two different items, 
each measuring one of these dimensions. Emotional wellbeing, which is measured by an item asking about importance and satisfaction in terms of the subjects' 'overall happiness', proved too difficult for proxies to answer and was dropped from the questionnaire.

\section{Results}

\section{Outcome}

Due to non-normality of data, non-parametric analyses were carried out in all cases. SPSS v.11.5 and R Language and Environment (R Development Core Team, 2007) packages were used.

The mean standardized score for adaptive behaviour on the ICAP was $24.4(\mathrm{SD}=27.1)$. Friedman's test showed that overall differences among the different subscales were significant $\left(\chi^{2}(3, N=74)=90.56, p<0.001\right)$. Although scores on the motor skills subscale were below population norms, they were higher (mean $=49.2, \mathrm{SD}=34.5$ ) than those found on the community living (mean $=21.7, \mathrm{SD}=25.0$ ), daily living (mean $=30.6$, $\mathrm{SD}=27.4$ ) or social/communication scales (mean $=31.1, \mathrm{SD}=30.6$ ). Bonferroni-corrected pairwise non-parametric comparisons showed that differences between all the subscales were significant $(p<0.001)$, except for daily living and social/communication skills. The service scores of the ICAP, which are derived from adaptive and disruptive behaviour scores and are indicative of the overall need for supervision, were consequently high: 20 percent required intense support, 26 percent limited support and 26 percent periodic support. Twenty-three percent of the participants, however, were reported as needing only sporadic supervision or none at all.

The mean score on the modified CARS was 29.6 (SD $=6.0$, range 19.5-44.5) out of a possible maximum of 56. Thirty-five percent of individuals had scores on this instrument that were indicative of severe autism, another 35 percent had light and moderate autism, and an additional 10 percent of scores were within three points of the cutoff score. Communication difficulties, as measured with the DAS scale, were severe in a large proportion of the participants. Fourteen percent, for example, were totally non-verbal, although only 3 percent did not understand language at all. Around two-thirds could communicate effectively with their families in daily activities. In most cases they did so in relatively simple terms (see Table 1). Approximately half (49\%) understood conversations about people, although the rest of those with some comprehension were only able to follow simple or practical instructions.

The quality of social interaction, as measured with the DAS disability scale, was extremely poor, with 49 percent of adults initiating at most social 
Table I Social and language outcome measures on the DAS (Holmes et al., 1982)

Receptive language

Lacking

$3 \%$

Simple orders

$24 \%$

Practical tasks

$24 \%$

Personal experiences or needs

$49 \%$

Expressive language

Lacking

Simple words or gestures $\quad 22 \%$

Words or gestures to express personal needs $\quad 23 \%$

Words or gestures to express personal experiences $\quad 17 \%$

Events that do not involve personal experiences $\quad 24 \%$

Social interaction

Does not establish relations

Seeks and responds only to physical contact $\quad 30 \%$

Establishes relations only to satisfy personal needs $\quad 15 \%$

$\begin{array}{ll}\text { Initiates social contact } & 8 \%\end{array}$

Maintains social contact with people he/she knows $\quad 10 \%$

Maintains contacts with other people $\quad 15 \%$

Reacts normally to social contacts $\quad 15 \%$

Immediate echolalia

Insufficient language $\quad 32 \%$

Rare or non-existent $\quad 53 \%$

Frequent $\quad 8 \%$

$\begin{array}{ll}\text { Daily } & 7 \%\end{array}$

Delayed echolalia

Insufficient language $\quad 32 \%$

Rare or non-existent $\quad 42 \%$

Frequent $14 \%$

$\begin{array}{ll}\text { Daily } & 12 \%\end{array}$

Complex stereotypical behaviour and routines

Absent or rare $\quad 25 \%$

Slight routines or obsessive behaviour $\quad 26 \%$

Intense and maladaptive stereotypes $\quad 49 \%$

interactions aimed at satisfying personal needs. Fifteen percent displayed social interactions appropriate to their mental age.

Seventy-six percent showed some form of need of routines, although this was only described as a 'slight adherence' in a quarter of the cases. Only 29 percent engaged in spontaneously initiated activities of some sort. 
Comparatively, health was not described as poor for most participants. Seventeen percent did require some form of regular medical assistance. However, 77 percent of the participants were under some form of medication, in 42 percent of the cases to control for epilepsy.

\section{Family and social network}

Eighty-seven percent of the adults lived with their parents. It was mothers that most often took care of them (54\%). Fathers were retired in 36 percent of the cases, and 66 percent of mothers had no other occupation.

Families were asked about the identity and number of members of three social networks: those who could help with personal everyday care issues, those who could provide emotional support, and those who could participate in leisure activities. When all of these domains were jointly considered, mothers were reported as the only member of the social network for 7 percent of the participants. In 34 percent of the cases, adults with ASD only had two different people in their social networks. Ninety-six percent of participants included their mothers in one of the networks, 74 percent their fathers, 65 percent extended family members, 39 percent siblings, 40 percent helpers and other practitioners, and only 9 percent friends. Table 2 shows the distribution of the members of the social networks relative to the total size of the network.

\section{Services and support}

Sixty-four percent of subjects were receiving one type of service, 19 percent were receiving two and one individual was benefiting from three (see Table 3). Sixteen percent were not taking part in any type of programme. Of the total participants, 32 percent were enrolled in a day centre, 16 percent were still in an educational centre, and 20 percent were in a work

Table 2 Social network of participants as described by proxies (percentages should be read across rows, and indicate proportion of persons within each network size that include a given figure)

\begin{tabular}{|c|c|c|c|c|c|c|}
\hline & Mother & Father & Siblings & $\begin{array}{l}\text { Extended } \\
\text { family }\end{array}$ & Friends & Professional \\
\hline One person & $60 \%$ & $20 \%$ & $0 \%$ & $0 \%$ & $0 \%$ & $20 \%$ \\
\hline Two more different people & $100 \%$ & $80 \%$ & $0 \%$ & $4 \%$ & $4 \%$ & $12 \%$ \\
\hline Three different people $\mathrm{e}^{\mathrm{a}}$ & $95 \%$ & $84 \%$ & $37 \%$ & $21 \%$ & $0 \%$ & $47 \%$ \\
\hline Four or more different people ${ }^{a}$ & $100 \%$ & $71 \%$ & $88 \%$ & $50 \%$ & $25 \%$ & $58 \%$ \\
\hline
\end{tabular}

${ }^{a}$ In these categories, participants sometimes had more than one sibling, extended family member, friend or professional in the network. 
Table 3 Number of individuals receiving each type of service with total number of different services received per individual

\begin{tabular}{llll}
\hline & \multicolumn{4}{l}{ Number of services received by each individual } \\
\cline { 2 - 4 } & $\begin{array}{l}\text { One } \\
(n=47)\end{array}$ & $\begin{array}{l}\text { Two } \\
(n=14)\end{array}$ & $\begin{array}{l}\text { Three } \\
(n=1)\end{array}$ \\
\hline Day centre & 15 & 8 & 1 \\
Educational centre & 11 & 1 & \\
Work scheme & 10 & 4 & \\
Residence & 9 & 1 & 1 \\
Family relief & 1 & 10 & 1 \\
Home support & 1 & 4 & 1 \\
\hline
\end{tabular}

a Twelve individuals received no service.

training scheme. This percentage rises to 26 percent if those at school are excluded. Only two individuals were actually employed.

Fourteen lived in a residential institution for severely disabled persons, although none were in supported housing or other kinds of residences. Only a small proportion of the individuals living with their family were receiving support at home $(9.4 \%)$. Nineteen percent of the families with a person with ASD at home were benefiting from some form of family relief programme. Ninety-two percent of the adults with ASD were receiving disability financial benefit.

\section{Subjective quality of life}

Of the total number of participating families, when presented with each of the items of the questionnaire, only 32 felt able to describe their relatives' satisfaction. Of these, 25 were capable of responding to five or more of the items (out of the seven in total) and were thus considered valid. The one or two missing data points in the satisfaction or importance scales of each of these questionnaires were replaced with the mean scores of the respondent for the scale (importance or satisfaction) in which the item was missing.

The willingness to act as a proxy was independent of the status of the informer (father or mother) or the diagnosis of the individual with ASD. However, it did relate to autistic symptoms and adaptive behaviour. Differences in overall ICAP and average CARS scores were significantly different between subjects whose parents were willing to act as proxies (mean = $41.8, \mathrm{SD}=9.3 ;$ mean $=25.8, \mathrm{SD}=4.9$, respectively) and those who could not $($ mean $=30.5, \mathrm{SD}=10.3$; mean $=31.5, \mathrm{SD}=5.6$ ) (Wilcoxon ranksum test $W=268$, exact $p<0.001$; and $W=936$, exact $p<0.001)$.

Importance scores reported by proxies varied significantly among domains (Friedman's test, $\left.\chi^{2}(6, N=25)=52.30, p<0.001\right)$. Bonferroni- 
corrected pairwise non-parametric comparisons showed that the domain of material wellbeing was significantly more important than all the others $(p<0.05)$, except for intimacy with the family. This domain was more important in the eyes of proxies than all the others, except for place in the community. Similarly, unweighted satisfaction scores also differed among domains (Friedman's test, $\left.\chi^{2}(6, N=25)=30.54, p<0.001\right)$. However, in this case, it was only satisfaction with material wellbeing that was significantly greater than safety and place in the community $(p<0.05)$ (see Table 4).

Means of satisfaction scores were multiplied by importance scores, and transformed to percentage scores following Cummins (1997). Overall scores obtained in this way reached a mean of 69.0 ( $\mathrm{SD}=10.1,48.3-86.5$ ). Percentage scores were significantly different among domains $\left(\chi^{2}(6, N=\right.$ $25)=50.77, p<0.001)$. Satisfaction with material wellbeing and with intimacy with family were significantly greater than with safety, heath or productivity, which in turn were higher than intimacy with friends.

However, no differences were found in overall percentage scores among individuals receiving different types of support, and no significant correlations were found between the size of social networks or individuals' autistic symptoms or their adaptive behaviour scores and subjective QoL. Percentage of satisfaction correlated positively with age (Spearman's rho $(25)=0.43, p=0.034$ ) and with ICAP services scores (rho $(25)=0.45$, $p=0.025)$. Correlations between these two variables were of a similar magnitude (rho $(25)=0.44, p=0.026)$.

\section{Discussion}

Results show a particularly poor outcome for adults with ASD in southern Spain. Although a high percentage were able to function with only occasional

Table 4 Mean importance and satisfaction raw scores and percentage scores by domain ( \pm SD) (5 is maximum score; $n=25$ )

\begin{tabular}{llll}
\hline & Importance & Satisfaction & Percentage \\
\hline Material wellbeing & $4.5 \pm 0.9$ & $4.3 \pm 0.7$ & 83.6 \\
Health & $3.6 \pm 1.2$ & $3.5 \pm 0.8$ & 63.3 \\
Productivity & $3.5 \pm 1.0$ & $3.7 \pm 0.7$ & 66.4 \\
Intimacy with family & $4.5 \pm 0.8$ & $4.2 \pm 0.7$ & 81.4 \\
Intimacy with friends & $2.8 \pm 1.2$ & $3.4 \pm 1.0$ & 55.8 \\
Safety & $4.1 \pm 0.8$ & $3.4 \pm 0.9$ & 61.3 \\
Place in community & $3.5 \pm 1.0$ & $3.9 \pm 0.8$ & 67.8 \\
\hline
\end{tabular}


supervision, adaptive behaviour and autistic symptom scores were especially poor.

None of the adults were living independently: nearly 90 percent were living with their families. Only two were employed, and three-quarters were not involved in any employment-related activity or training at all. The results are clearly worse than those of the general population of young adults: in Andalusia, 47 percent of the population was working in the 16 to 24 age bracket, and 80.9 percent was doing so among those aged 25 to 34 (Instituto de Estadística de Andalucía, 2005). The figures are also worse than those found overall for persons with disabilities in Andalusia, among whom 22.4 percent were working at that time (Consejería de Empleo, 2007). In addition, 16 percent of the participating adults in our study were still in educational centres by virtue of Spanish legislation that allows pupils with special educational needs to remain at school until the age of 21 . This is clearly greater than the legal working age of 16 and the average age of 18 for post-compulsory secondary education.

Their social networks were very limited. In around 30 percent of cases, adults with ASD only had two different people in their social networks, who, for most of them, were their mother and father.

These data are similar to those found in earlier research looking into adult outcomes in other countries (Howlin et al., 2000; Mawhood et al., 2000; Rutter, 1970). As in those studies, it seems clear from the outcome data that our participants have great cognitive, social and communicative limitations. The number of participants with a diagnosis of Asperger syndrome, for example, is strikingly low. This does not seem to be a particular bias of the persons responding to our study. We believe it is rather a reflection of the kind of individuals that have been more easily detected and diagnosed by the social and health services: the proportion of participants with Asperger syndrome was actually greater in the families that were interviewed than among the subjects who took part in a broader study into adult prevalence of ASD in Andalusia (Saldaña et al., 2006).

However, it is difficult to determine whether the observed outcome is the result of individuals' personal capabilities or the support provided. Although most participants were involved in some form of programme or institution, inclusion-oriented services were greatly lacking. A third were attending day centres and 14 percent were in residential institutions. Twenty percent were in employment programmes, and 16 percent still in secondary education. Whereas these last two could still be considered competency building programmes, this is not always the case for the day centres and the residential institutions. At the same time, most of the support was dependent on families. Families, in turn, generally did not receive organized support other than financial aid: only a quarter of them were recipients of 
family relief or home support programmes. Support for these families, therefore, still remains a major challenge to the social services (Hare et al., 2004).

This situation contrasts with the data on subjective quality of life as reported by proxies. These data coincide with previous studies with families and persons with disabilities (Verdugo et al., 2005) but must, at the same time, be accepted with caution. Slightly fewer than half the participating families felt able to complete the QoL questionnaires. The main determining factor in being able to do so was the person with ASD's adaptive behaviour and autistic symptoms. In the more severe cases, parents did not feel confident enough to be able to rate the importance or degree of satisfaction of the participant. At the same time, satisfaction correlated positively with the ICAP service provision score. It is, therefore, plausible that if the families with the lower-functioning individuals had been able to respond, they would have done so with a lower range of scores.

The role of the individuals' personal limitations in determining subjective quality of life as evaluated by proxies is, however, unclear in our study. Age, need for service provision and subjective QoL are closely correlated. It is therefore also possible that the situation of younger adults, who are just leaving school and finding themselves mostly without the additional resources necessary for a successful adult life with inclusion into the community, could be influencing the informants' negative perceptions. This interpretation would be in line with the results of Renty and Royers (2006) who found that perceived support, and not personal characteristics, was the best predictor of QoL.

The study does, of course, include a limited number of participants, mostly related to support groups. They are mainly the individuals with greater difficulties and associated intellectual disabilities who have been identified by the social and educational services and therefore included in the study. This profile is coherent with recent research that has shown that children with ASD in families that belong to support groups tend to have children with more severe problems (Mandell and Salzer, 2007). It is very possible that higher-functioning adults with ASD show different outcome to what has been found. It is unlikely, however, that they are receiving additional support. The database for participants in this study was obtained precisely from service providers. It is more likely that higher-functioning individuals with ASD in Andalusia have not been identified as such.

Finally, this study once again highlights the difficulties of using proxy measures to determine the QoL of individuals with severe disabilities. It is very striking that over half of the families were not even able to forward an approximation of the satisfaction of the person with ASD. This, once again, speaks of the difficulty of interpreting personal wellbeing in individuals 
whose major handicap is precisely of a social and communicative nature. There is clearly a call for changes in the way QoL is measured in the population with ASD and communicative and cognitive limitations. This will most likely only be possible following a conceptual revision of how the traditional domains of QoL should be interpreted in the cases of individuals with severe disabilities.

\section{Acknowledgements}

The present data are part of a wider study into the prevalence, service demands and family support needs of adults with ASD (Saldaña et al., 2006). This research was possible thanks to a grant from the Servicio Andaluz de Empleo (Andalusian Employment Service) and the financial support of Autismo Andalucía. The authors wish to thank the participating families and adults. Contact with the participants was possible thanks to the collaboration of the Consejería para la Igualdad y Bienestar Social (Regional Ministry for Equal Opportunities and Social Welfare), the Centros de Valoración y Orientación (Centres for Assessment and Counseling), FEAPS Andalucía (the Andalusian Federation of Support Groups for Persons with Intellectual Disabilities) and various clinicians and practitioners.

\section{References}

Aguilera, A., Moreno, F.J. \& Rodríguez (2007) 'The Prevalence Estimates of Autism Spectrum Disorders in the School Population of Seville, Spain’, British Journal of Developmental Disabilities 53: 97-109.

Ballaban-Gil, K., Rapin, I., Tuchman, R. \& Shinnar, S. (1996) 'Longitudinal Examination of the Behavioral, Language, and Social Changes in a Population of Adolescents and Young Adults with Autistic Disorder', Pediatric Neurology 15: 217-23.

Belinchón, M. (2001) Situación y necesidades de las personas con trastornos del espectro autista en la Comunidad de Madrid (Situation and Needs of Persons with Autism Spectrum Disorders in the Region of Madrid). Madrid: M\&M.

Billstedt, E., Gillberg, I.C., Gillberg, C. \& Gillberg, C. (2005) 'Autism after Adolescence: Population-Based 13- to 22-Year Follow-Up Study of 120 Individuals with Autism Diagnosed in Childhood', Journal of Autism and Developmental Disorders 35: 351-60.

Billstedt, E., Gillberg, C. \& Gillberg, C. (2007) 'Autism in Adults: Symptom Patterns and Early Childhood Predictors. Use of the DISCO in a Community Sample Followed from Childhood', Journal of Child Psychology and Psychiatry 48: 1102-10.

Bruininks, R.H., Hill, B.K., Woodcock, R.W. \& Weatherman, R.F. (1993) Inventario para la planificación de servicios y programación individual ICAP (Inventory for Client and Agency Planning ICAP). Bilbao: ICE Deusto/Mensajero.

Consejería de Empleo (2007) Plan de Empleabilidad para Personas con Discapacidad en Andalucía 2007-2013 (Employment Plan for Persons with Disabilities in Andalusia 2007-2013). Seville.

Cummins, R. (1997) 'Comprehensive Quality of Life Questionnaire-Intellectual Disability', Deakin University.

Eaves, L. \& Ho, H. (in press) 'Young Adult Outcome of Autism Spectrum Disorders', Journal of Autism and Developmental Disorders. 
Gillberg, C. \& Steffenburg, S. (1987) 'Outcome and Prognostic Factors in Infantile Autism and Similar Conditions: A Population-Based Study of 46 Cases Followed through Puberty', Journal of Autism and Developmental Disorders 17: 273-87.

Hare, D.J., Pratt, C., Burton, M., Bromley, J. \& Emerson, E. (2004) 'The Health and Social Care Needs of Family Carers Supporting Adults with Autistic Spectrum Disorders', Autism 8: 425-44.

Holmes, N., Shah, A. \& Wing, L. (1982) 'The Disability Assessment Schedule: A Brief Screening Device for Use with the Mentally Retarded’, Psychological Medicine 12: 879-90.

Howlin, P., Mawhood, L. \& Rutter, M. (2000) 'Autism and Developmental Receptive Language Disorder: A Comparative Follow-Up in Early Adult Life. II: Social, Behavioural, and Psychiatric Outcomes', Journal of Child Psychology and Psychiatry 41: 561-78.

Howlin, P., Goode, S., Hutton, J. \& Rutter, M. (2004) 'Adult Outcome for Children with Autism’, Journal of Child Psychology and Psychiatry 45: 212-29.

Instituto de Estadística de Andalucía (2005) 'Encuesta de Población Activa. Andalucía. Datos Anuales 2005' ('Active Population Survey. Andalusia. Annual Data 2005’). http://www.juntadeandalucia.es/iea/epa/2005/epaAnual2005Ind01.htm.

Kobayashi, R., Murata, T. \& Yoshinaga, K. (1992) ‘A Follow-Up Study of 201 Children with Autism in Kyushu and Yamaguchi Areas, Japan’, Journal of Autism and Developmental Disorders 22: 395-411.

Lotter, V. (1974a) 'Social Adjustment and Placement of Autistic Children in Middlesex: A Follow-Up Study', Journal of Autism and Childhood Schizophrenia 4: 11-32.

Lotter, V. (1974b) 'Factors Related to Outcome in Autistic Children', Journal of Autism and Childhood Schizophrenia 4: 263-77.

Mandell, D.S. \& Salzer, M.S. (2007) 'Who Joins Support Groups among Parents of Children with Autism?', Autism 11: 111-22.

Mawhood, L., Howlin, P. \& Rutter, M. (2000) 'Autism and Developmental Receptive Language Disorder: A Comparative Follow-Up in Early Adult Life. I: Cognitive and Language Outcomes', Journal of Child Psychology and Psychiatry 41: 547-59.

R Development Core Team (2007) R: A Language and Environment for Statistical Computing. Vienna: R Foundation for Statistical Computing. http://www.R-project.org.

Renty, J.O. \& Roeyers, H. (2006) 'Quality of Life in High-Functioning Adults with Autism Spectrum Disorder: The Predictive Value of Disability and Support Characteristics', Autism 10: 511-24.

Rumsey, J.M., Rapoport, J.L. \& Sceery, W.R. (1985) 'Autistic Children as Adults: Psychiatric, Social and Behavioural Outcomes', Journal of the American Academy of Child Psychiatry 24: 465-73.

Rutter, M.L. (1970) 'Psycho-Social Disorders in Childhood, and Their Outcome in Adult Life', Journal of the Royal College of Physicians of London 4: 211-18.

Saldaña, D., Álvarez, R., Moreno, M., López, A.M., Lobatón, S. \& Rojano, M. (2006) Vida Adulta y Trastornos del Espectro Autista: Calidad de Vida y Empleo (Adult Life and Autism Spectrum Disorders: Quality of Life and Employment). Sevilla: Autismo Andalucía.

Schalock, R.L. (2004) 'The Concept of Quality of Life: What We Know and Do Not Know', Journal of Intellectual Disability Research 48: 203-16.

Schalock, R.L. \& Verdugo, M.A. (2002) Handbook on Quality of Life for Human Support Practitioners. Washington, DC: American Association on Mental Retardation.

Schopler, E., Reichler, R.J., Devellis, R.F. \& Daly, K. (1980) 'Toward Objective Classification of Childhood Autism: Childhood Autism Rating Scales (CARS)', Journal of Autism and Developmental Disorders 10: 91-103. 
Tantam, D. (1991) ‘Asperger’s Syndrome in Adulthood’, in U. Frith (ed.) Autism and Asperger Syndrome, pp. 147-83. Cambridge: Cambridge University Press.

Venter, A., Lord, C. \& Schopler, E. (1992) 'A Follow-Up Study of High-Functioning Autistic Children', Journal of Child Psychology and Psychiatry 33: 489-507.

Verdugo, M.A., Schalock, R.L., Keith, K.D. \& Stancliffe, R.J. (2005) 'Quality of Life and Its Measurement: Important Principles and Guidelines', Journal of Intellectual Disability Research 49: 707-17. 